\title{
Granular Activated Carbon Produced from Asphalt*
}

\author{
by Tozo Amemiya**, Hiroshi Miyake**, Akira Yokogawa**, Mitsuyuki Mitooka**, \\ Shigeo Milsui***, Katsuji Ishibashi***, Jun-ichi Kawabata***, \\ and Yoneshiro Tazaki***
}

\begin{abstract}
Summary: 1 process for preparing granular activated carbon has been developed, utilizing petroleum residues such as asphalt. Successful pilot plant operations have been made.

The process consists of three steps. They are char production, char activation, and exhaust gas treating. Granular char, hard and uniform, has been produced by reacting asphalt with fuming sulfuric acid or elemental sulfur.

A co-current, two-step fluidized bed furnace with unique features developed by the authors has been used for activating char above obtained.

The product has indicated some excellent properties such as large specific surface area, extensive methylene blue adsorption, characteristic pore distribution, and high mechanical strength. Some practical applications have shown promising results.
\end{abstract}

\section{Introduction}

Activated carbon, especially granular activated carbon, is one of the essential materials used for prevention of air and water pollutions, and its demand is constantly increasing. Fresh water supply in Japan is limited, and its shortage will be a serious problem in the near future. The Ministry of Construction has estimated that in 1985 water demand in Japan will be $170 \%$ greater than that in 1965.

Up to now, woody materials such as coconut shells and sawdust have been valued as sources of activated carbon of good quality. But supplies of these raw materials are limited. Processes for production of activated carbon from coal have recently been developed, but they are only in limited commercial operation. Also these processes involve complicated steps, and they are not easily adaptable to large scale operations. Moreover, supply of coals with desirable properties for activated carbon production is limited.

The various materials mentioned above cannot be considered as dependable sources. On the other hand, the heavy fractions of petroleum, such as asphalt, are readily available, and they

* Recived December 27, 1974

* Research and Development Center, Maruzen Oil Co., Ltd. (Gongendo, Satte-machi, Kitakatsushikagun, Saitama-ken, 340-01)

*** The Government Industrial Development Laboratory, Hokkaido, (Higashi-tsukisamu, Toyohira-ku, Sapporo-shi, 061-01) can be important sources of activated carbon. To develop a new process for large scale production of good quality activated carbon from these fractions, we have made studies using asphalts since 1970, and we are now operating a pilot plant using the process successfully.

\section{Process Description}

\subsection{Process Flow Scheme}

Figure 1 shows a flow diagram of the new process for producing activated carbon from asphalt. The process consists essentially of the following three steps: (1) char producing step, (2) char activating step, and (3) exhaust gas treating step.

Two different processes, as shown in Fig. 1, were used for the char producing step.

\subsubsection{Char Producing Procedure}

Petroleum residue or asphalt as a raw material was treated with sulfuric acid or fuming sulfuric acid in Process A. The purpose was to obtain a char with high melting point by sulfonation, oxidation, and dehydrogenation reactions. These reactions were carried out in a paraffinic or halogenated hydrocarbon solvent under vigorous agitation at $70 \sim 100^{\circ} \mathrm{G}$ for $1 \sim 3$ hours.

In Process $\mathrm{B}$, the raw material was reacted with elemental sulfur to obtain a char by dehydrogenation. The reaction was carried out in kerosene or gas oil used as solvent at 200 230 C: for $2 \sim 4$ hours.

Solvents in both processes were recovered by distillation, and the grainy chars of varying

Volume 17, No. 1, April 1975 

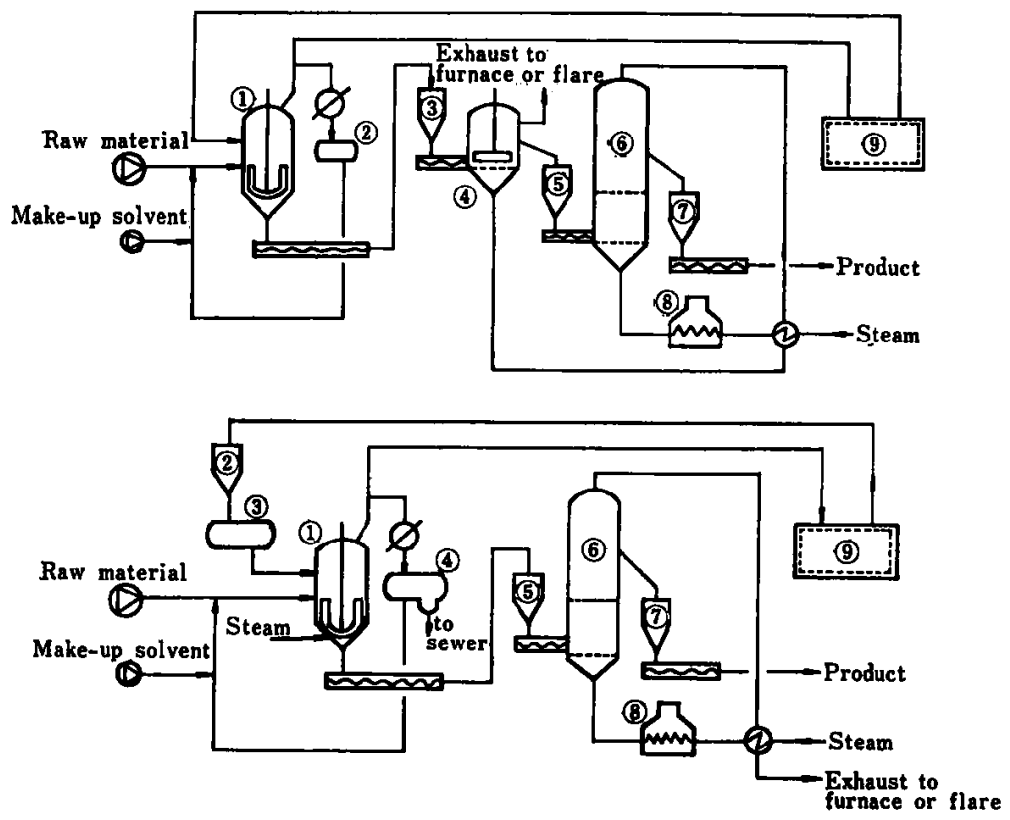

Process A

1. Reactor for char production

2. Solvent receiver

3. Char hopper

4. Drying and carbonizing furnace (Agitating fluidized bed)

5. Char hopper

6. Activating furnace

7. Product hopper

8. Steam heater

9. $\mathrm{SO}_{2}$ oxidizing unit

\section{Process B}

1. Reactor for char production

2. Sulfur hopper

3. Sulfur melter

4. Solvent separator

5. Char hopper

6. Activating (Co-current twostep fluidized bed)

7. Product hopper

8. Steam heater

9. Sulfur recovery unit (Claus plant)

Fig. 1 Schematic Flow Diagram of the Process

sizes from about 1 to $5 \mathrm{~mm}$ in diameter remained. Such gases as $\mathrm{SO}_{2}$ (from Process $A$ ) and $\mathrm{H}_{2} \mathrm{~S}$ (from Process $\mathrm{B}$ ) produced in the reaction were subjected to gas treating, and the $\mathrm{SO}_{2}$ recovered could be converted to sulfuric acid and $\mathrm{H}_{2} \mathrm{~S}$ to elemental sulfur. The yield of char from either process was from 120 to $160 \%$ by weight of the raw material used.

\subsubsection{Char Activating Step}

The char thus obtained was activated with steam at $850 \sim 900^{\circ} \mathrm{C}$ in our co-current, twostep fluidized bed furnace ${ }^{1)}$ where steam was also used for fluidization, and activation could be done continuously and efficiently. Both steam and char were charged at the lower zone of the fluidized bed, and activated carbon was obtained from the upper zone. This is quite possible, because the density of activated carbon particles is smaller than that of the char. This is one of the unique features of our process.

The yield of activated carbon from the char was from 30 to $40 \%$ by weight. The yield based on asphalt was from 30 to $45 \%$ by weight.

\subsubsection{Exhaust Gas Treatment}

In Process $A$, the exhaust gas generated from the char producing step and the char activating step was substantially $\mathrm{SO}_{2}$, which could be oxidized catalytically to sulfuric acid. $\mathrm{H}_{2} \mathrm{~S}$ was generated from Process $B$ and it was converted to elemental sulfur by the Claus process. Both sulfuric acid and elemental sulfur thus recovered could be reused.

\subsection{Process Characteristics and Economy}

Although a number of reports are available for reactions between petroleum residues and sulfuric acid or elemental sulfur, there are only few reports concerned with the production of activated carbon ${ }^{2) ~ 4) . ~ M o r e o v e r, ~ t h e ~ c h a r ~ p r o-~}$ duced by these reactions is usually lumpy and brittle, and additional steps such as pulverizing and pelletizing are required for manufacturing granular activated carbon of high quality.

In our process, however, the reaction was carried out in the liquid phase and granular char was precipitated from the reaction mixture. So, it was possible to obtain a hard char of almost uniform particle size.

The char was so easy to handle and it could be activated smoothly in the fluidized state, without the need for pulverizing or pelletizing, to produce high quality granular activated carbon.

Since the co-current, two-step fluidized furnace for activation is used in our process, activation can be done continuously with high thermal efficiency. This makes the commercial plant compact and simple that enhances the possibility of mass production of activated carbon.

Generally, the yield of activated carbon from coal used as the raw material is about $20 \%{ }^{5), 6)}$, while the yield from asphalt by our process is from 30 to $45 \%$ by weight of asphalt used. 
Since the solvents, sulfuric acid or elemental sulfur used can easily be recovered and reused, the process can be operated in a closed system. About $85 \%$ or more of the sulfuric acid used as reactant can be recovered and reused in Process A. About $75 \%$ or more of elemental sulfur used as reactant can be recovered and reused in Process B.

Table 1 gives construction costs and utilities requirements for Process B. It should be noted that activated carbon can be produced quite economically from asphalt by our process.

\section{Properties of Activated Carbon}

\subsection{Basic Properties}

Table 2 shows some of the properties of activated carbon A (product of Process A), B (product of Process B), C (market product), and D (market product). A and B have higher specific surface areas and high methylene blue adsorption. Pore distributions are also shown in Fig. 2. The existence of many micropores (under $15 \AA$ pore radius) $)^{7}$ is remarkable in $A$, while the existence of transitional pores (from $15 \AA$ to $1,000 \AA$ pore radius) ${ }^{7}$ ) is remarkable in $\mathrm{B}$. It is presumed that this is the reason why the products from Process $A$ and $B$ indicate such high

Table 1 Typical Economics

\begin{tabular}{l|c}
\hline Plant Capacity & $5,000 \mathrm{t} / \mathrm{yr}$ \\
Investment Cost & $1,860 \% 10^{6} \mathrm{Yen}$ \\
Raw Materials (per product ton) & $2.2 \mathrm{t}$ \\
ItAsphaltic Petroleum Residue & $0.3 \mathrm{t}$ \\
Heavy Gas Oil & $0.8 \mathrm{t}$ \\
Sulfur & $620 \mathrm{~kW} \cdot \mathrm{hr}$ \\
Utilities & $5.9 \mathrm{t}$ \\
Electricity & $89 \mathrm{t}$ \\
Steam & $1.5 \times 10^{6} \mathrm{kcal}$ \\
Industrial Water & \\
Fuel & \\
\hline
\end{tabular}

specific surface areas. Figures 3, 4, 5 and 6 show the surfaces of four species of activated carbon, enlarged 4,500 times by a scanning electron microscope. The surface of A or B differs from that of the market products, and the presence of small pores is clearly shown on the surfaces of $A$ and $B$.

Mechanical strength of the activated carbons were measured by the modified method of JIS $\mathrm{K} 1412^{8}$ ). B was found to be superior in me-

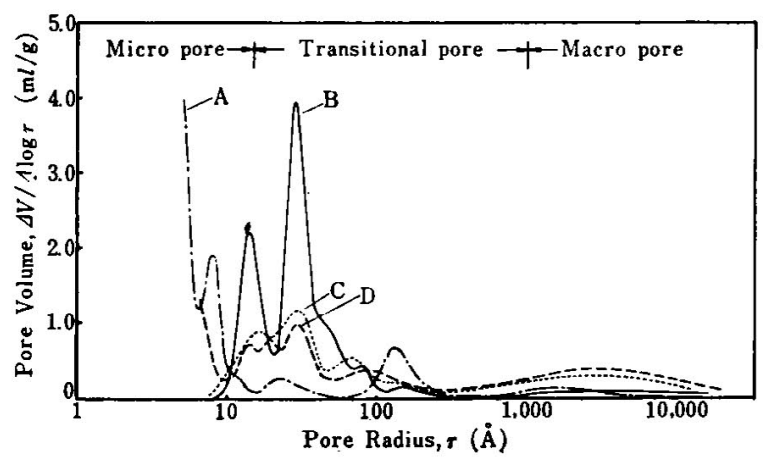

A: Process A product, B: Process B product, C: Market product, D: Market product

Fig. 2 Pore Distribution of Activated Carbon

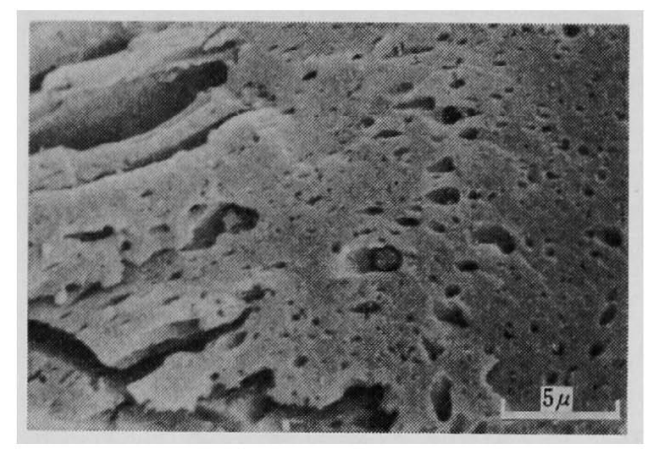

Fig. 3 Electron Microphotograph of Activated Carbon A (Process A Product)

Table 2 Characteristics of Typical Activated Carbons

\begin{tabular}{|c|c|c|c|c|}
\hline Activated Carbon & (Process A Product) & (Process B Product) & $\begin{array}{c}\mathrm{C} \\
\text { (Market Product) }\end{array}$ & $\frac{\mathrm{D}}{\text { (Market Product) }}$ \\
\hline $\begin{array}{l}\text { Specific Surface Area }\left(\mathrm{m}^{2} / \mathrm{g}\right) \\
\text { Pore Volume }(\mathrm{ml} / \mathrm{g}) \\
\text { Adsorption of Methylene Blue }(\mathrm{mg} / \mathrm{g}) \\
\text { Bulk Density }(\mathrm{g} / \mathrm{ml}) \\
\text { Mechanical Strength* }(\%) \\
\text { Size Distribution }(\mathrm{wt} \%) \\
8 \text { mesh over } \\
8 \sim 12 \text { mesh } \\
12 \sim 16 \text { mesh } \\
16 \sim 24 \text { mesh } \\
24 \sim 32 \text { mesh } \\
32 \text { mesh under }\end{array}$ & $\begin{array}{c}1,250 \\
1.29 \\
356 \\
0.40 \\
70 \\
\\
1 \\
4 \\
23 \\
35 \\
28 \\
9\end{array}$ & $\begin{array}{c}1,190 \\
1.31 \\
359 \\
0.44 \\
91 \\
\\
1 \\
5 \\
29 \\
40 \\
20 \\
5\end{array}$ & $\begin{array}{c}1,040 \\
0.99 \\
324 \\
0.42 \\
68 \\
\\
0 \\
2 \\
50 \\
29 \\
13 \\
6\end{array}$ & $\begin{array}{c}775 \\
0.85 \\
134 \\
0.42 \\
65 \\
1 \\
3 \\
38 \\
42 \\
10 \\
6\end{array}$ \\
\hline
\end{tabular}

* Mechanical strength was measured by the modified method of JIS $\mathrm{K} 1412$ as follow: 17 18 $\mathrm{g}$ of activated carbon sieved into 24 32 mesh range were charged in the steel-bound mill, and the carbon was crushed by 10 steel-bound balls $(10 \mathrm{~mm} \psi)$ with rotating the mill at $100 \mathrm{rpm}$ for 60 minutes. Then the activated carbon was sieved into $24 \sim 32$ mesh range, and its weight was determined. 


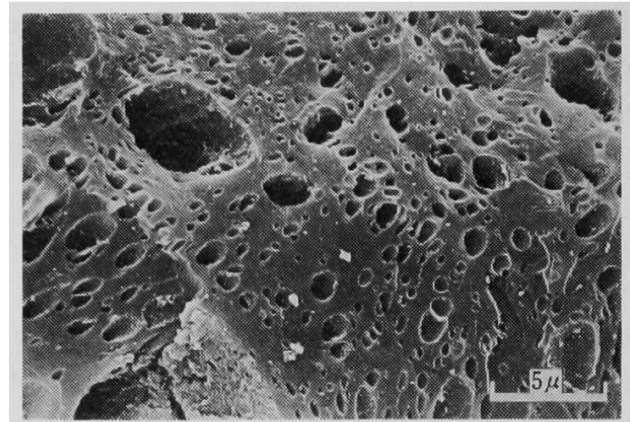

Fig. 4 Electron Microphotograph of Activated Carbon B (Process B Product)

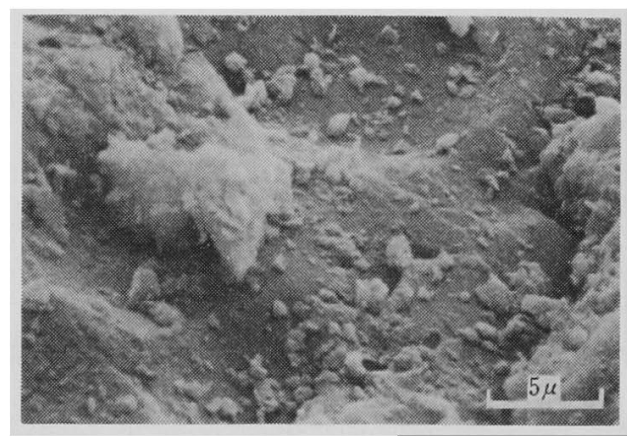

Fig. 5 Electron Microphotograph of Activated Carbon G (Market Product)

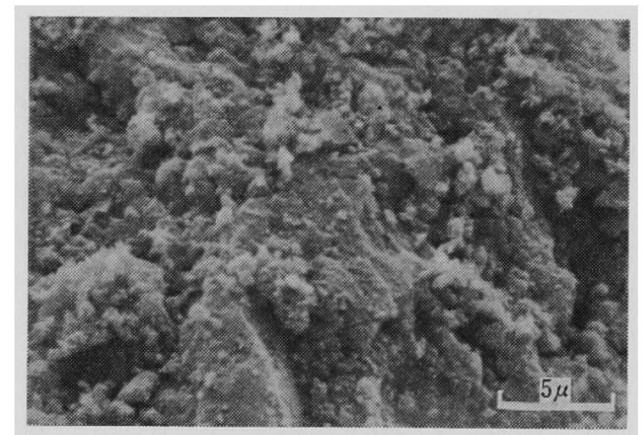

Fig. 6 Electron Microphotograph of Activated Carbon D (Market Product)

chanical strength to the others.

\subsection{Adsorption Characteristics}

The adsorption characteristics of activated carbons were examined by determining the adsorption isotherms and rates.

The change in the amount of adsorption with time and the amount of adsorption at equilibrium in both vapor phase and liquid phase were determined. The relationship between the equilibrium pressure or concentration and the amount of adsorption was summarized according to Freundlich's formula of adsorption $(1)^{9), 10)}$.

$$
\log Q_{\infty}=\frac{1}{n} \log q+K
$$

$Q_{\infty}$ is the amount of adsorption at equi-

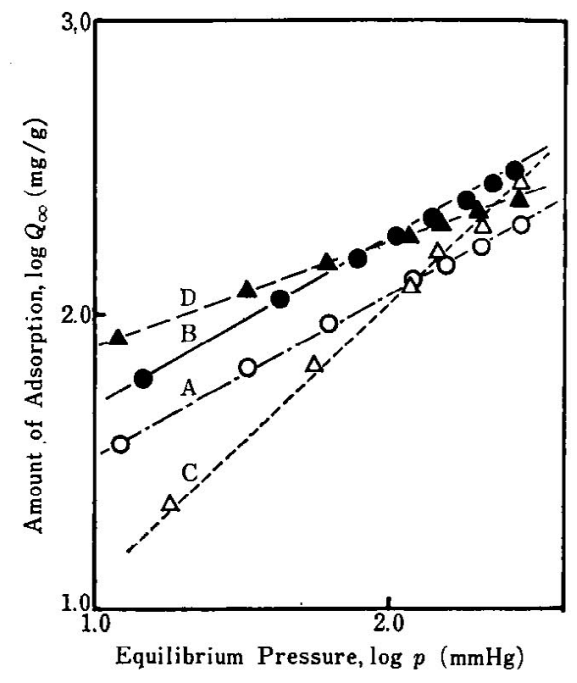

A: Process A product $(1 / n=0.63, K=1.08)$

B : Process B product $(1 / n=0.72, K=1.47)$

C: Market product $(1 / n=0.95, K=0.18)$

D : Market product $(1 / n=0.37, K=1.68)$

Fig. 7 Absorption Isotherm of $\mathrm{SO}_{2}\left(50^{\circ} \mathrm{G}\right)$

librium, $\mathrm{q}$ is the equilibrium pressure or concentration, and $1 / \mathrm{n}$ and $\mathrm{K}$ are constants. A small $1 / \mathrm{n}$ means a slight change in adsorption capability with change of equilibrium pressure or concentration, and a large $\mathrm{K}$ indicates a large amount of adsorption.

The change in the amount of adsorption with time was summarized according to Boyd's equation $(2)^{11)}$.

$$
\frac{Q_{\mathrm{t}}}{\mathrm{Q}_{\infty}}=\frac{6}{\mathrm{R}} \sqrt{\frac{\overline{\mathrm{D}_{\mathrm{i}} \cdot \mathrm{t}}}{\pi}}
$$

$R$ is the average radius of activated carbon particles, $D_{i}$ is the internal diffusion constant, and $t$ is time.

Generally, the rate of diffusion within the pores is considered to be the rate-determining step $^{11)}$.

As an example of the results in vapor phase adsorption, the adsorption isotherms and adsorption rates of $\mathrm{SO}_{2}$ are shown in Fig. 7 and 8 . As an example of liquid phase adsorption, the results of methylene blue adsorption are shown in Fig. 9 and 10.

In the vapor phase adsorption, $\mathrm{A}$ and $\mathrm{B}$ have characteristics similar to those of market product C or D. On the other hand, in the liquid phase adsorption, $\mathrm{A}$ and $\mathrm{B}$ show better adsorption characteristics than those of $\mathrm{C}$ or $\mathrm{D}$. Especially for high molecular weight substances, $\mathrm{A}$ and $\mathrm{B}$ incline to give higher adsorption rates than those of the market products. 


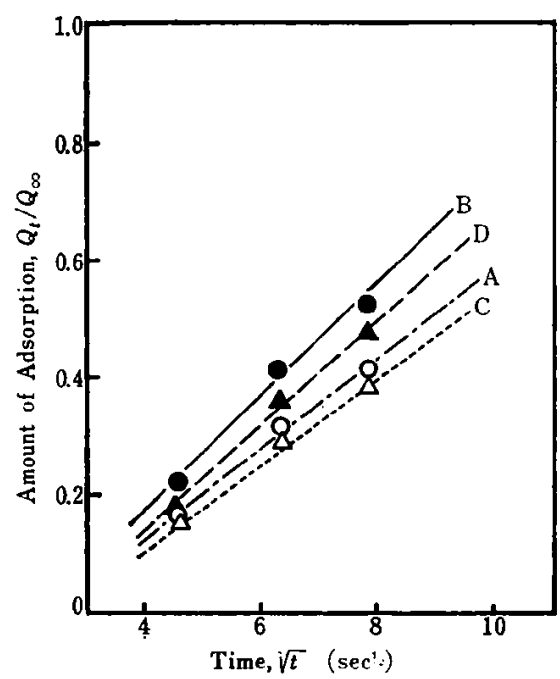

A: Process A product $\left(D_{i}=4.2 \times 10^{-6} \mathrm{~cm} / \mathrm{scc}\right)$

B : Process B product $\left(D_{i}=5.0 \div 10^{-6} \mathrm{~cm} / \mathrm{sec}\right)$

C: Market product $\left(D_{i}=4.4 \times 10^{-6} \mathrm{~cm} / \mathrm{sec}\right)$

D : Market product $\left(D_{i}=4.9,10^{-6} \mathrm{~cm} / \mathrm{sec}\right)$

Fig. 8 Adsorption Rate of $\mathrm{SO}_{2}\left(50^{\circ} \mathrm{C}\right)$

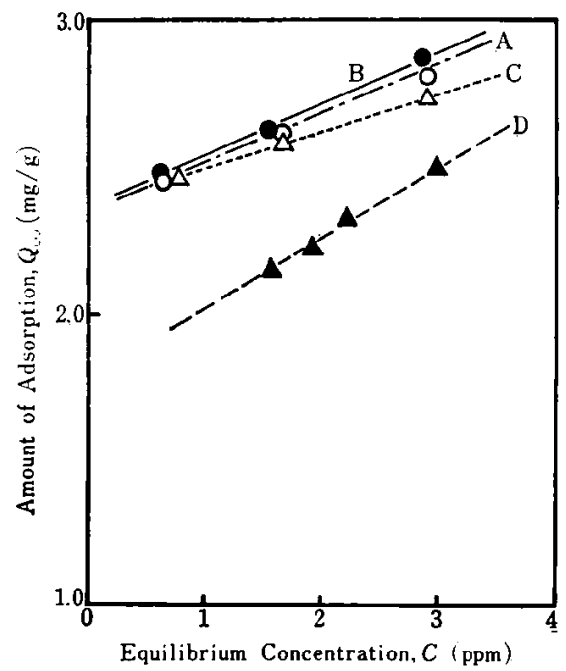

A : Process A product $(1 / n=0.17, K=238)$

B : Process B product $(1 / n=0.16, K=250)$

C: Market product $(1 / n=0.12, K=245)$

D : Market product $(1 / n=0.23, K=65)$

Fig. 9 Adsorption Isotherm of Methylene Blue $\left(25^{\circ} \mathrm{C}\right)$

\subsection{Performance Test}

Two experiments were carried out to test the performance of our activated carbon in the vapor and liquid phase applications. As an example of vapor phase application, capability for prevention of motor gasoline vaporization was determined by Toyota Motor's Test Method, which consists of vapor phase adsorption and desorption of benzene on activated carbon. A $150 \mathrm{~g}$ sample of activated carbon was introduced

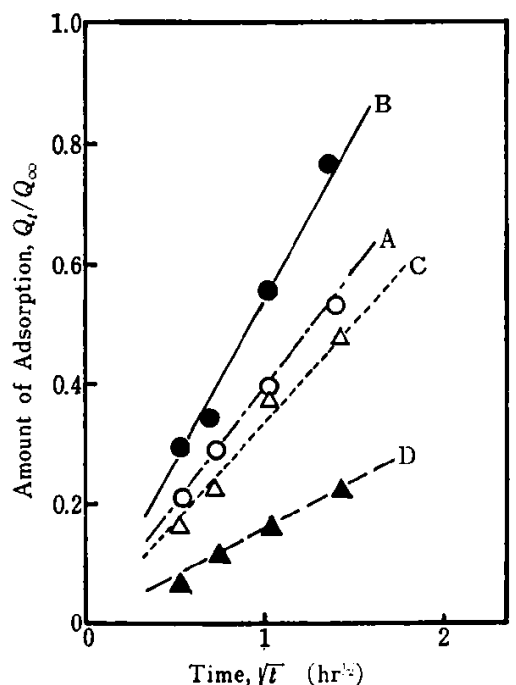

A: Process A product $\left(D_{i}=1.2 \times 10^{-8} \mathrm{~cm} / \mathrm{sec}\right)$

B : Process B product $\left(D_{i}=1.7 \times 10^{-\mathrm{B}} \mathrm{cm} / \mathrm{sec}\right)$

C: Market product $\left(D_{i}=0.94 \times 10^{-8} \mathrm{~cm} / \mathrm{sec}\right)$

D : Market product $\left(D_{i}=0.29 \times 10^{-8} \mathrm{~cm} / \mathrm{sec}\right)$

Fig. 10 Adsorption Rate of Methylene Blue $\left(25^{\circ} \mathrm{C}\right)$

into a U-tube to form a layer, and benzene vapor was passed through it at the rate of $400 \mathrm{~m} l /$ $\min$ at $25^{\circ} \mathrm{C}$ until the weight of the adsorbent layer became constant. The results are shown in Fig. 11 (1).

In the desorption experiment, air was passed through the activated carbon layer, which had adsorbed benzene, at the rate of $400 \mathrm{~m} l / \mathrm{min}$ at $25^{\circ} \mathrm{C}$, and the decrease in the weight of the adsorbent layer with time was determined. The results are shown in Fig. 11 (2).

As for the activated carbon used to prevent motor gasoline vaporization, it is desirable that the activated carbon has a high rate of and capacity for adsorption of hydrocarbons (benzene) and a high rate of desorption of hydrocarbons (benzene). The market products $\mathrm{E}$ and $\mathrm{F}$ are used industrially for this purpose. The products A and B are expected to be more useful, because they have better adsorption and desorption characteristics than those of $E$ and $F$.

As an example of liquid phase applications, the removal of phenol from FCC waste water was tested with activated carbon. The FCC waste water contained about $100 \mathrm{ppm}$ of phenols and about $200 \mathrm{ppm}$ of $\mathrm{H}_{2} \mathrm{~S}$. Since the latter might interfere with the adsorption of phenols, it was removed prior to the adsorption experiment by bubbling air through the waste water, which was then charged to the $150 \mathrm{~g}$ activated carbon layer at the rate of $6 / / \mathrm{hr}$. The 


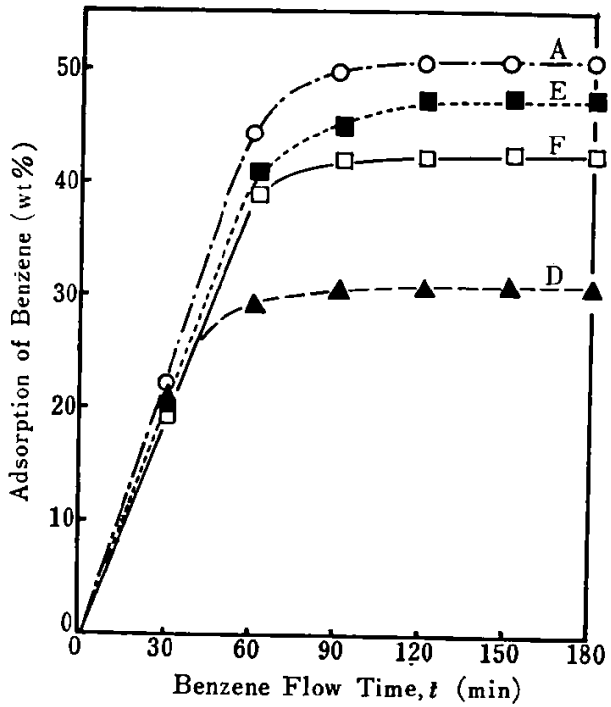

( 1 ) Adsorption test of benzene $\left(25^{\circ} \mathrm{C}\right)$ Activated carbon: $150 \mathrm{~g}$ Benzene flow rate: $400 \mathrm{ml} / \mathrm{min}$

E : Market product used in canister Air flow

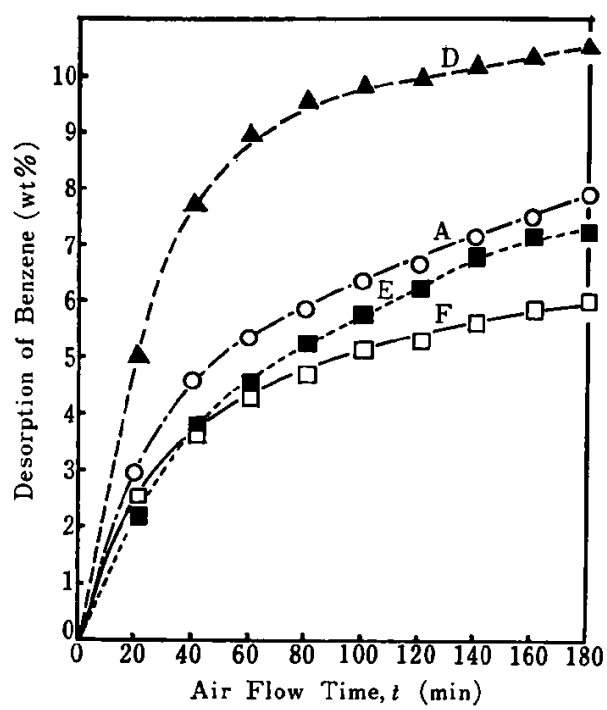

(2) Desorption test of benzene $\left(25^{\circ} \mathrm{C}\right)$ Activated carbon: $150 \mathrm{~g}$ Air flow rate: $400 \mathrm{ml} / \mathrm{min}$

Fig. 11 Evaluation of Prevention Ability of Carbon against Exhaust of Hydrocarbon Vapor from Gasoline Tank of Car

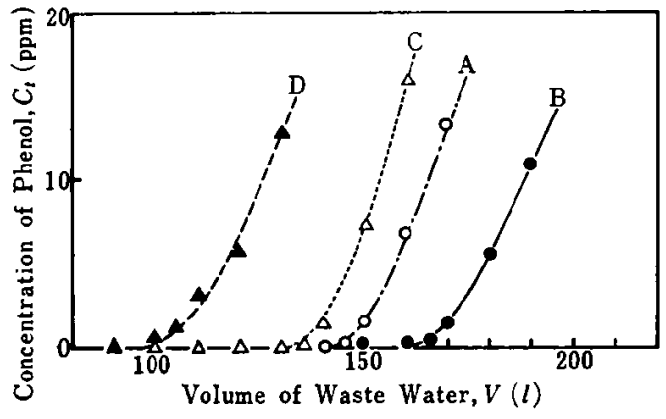

Activated carbon: $150 \mathrm{~g}(16 \sim 32 \mathrm{mesh})$

Waste water flow rate: $6 l / \mathrm{hr}$

Phenol content in waste water: $100 \mathrm{ppm}$

A : Process A product (Break-through point: $147 l$ )

B : Process B product (Break-through point: 165l)

C: Market product (Break-through point: $137 l$ )

D: Market product (Break-through point: $98 l$ )

Fig. 12 Break-through Curves of Phenol $\left(25^{\circ} \mathrm{C}\right)$

break-through curves are shown in Fig. 12. The break-through point is defined as the point at which the phenol content in the effluent from the activated carbon column attains a value of $0.3 \mathrm{ppm}$.

\section{Conclusion}

We have developed a new and unique process for economical production of granular activated carbon from asphalts.

To produce a char, which can withstand high activating temperatures such as $850 \sim 900^{\circ} \mathrm{C}$, from petroleum fractions of low softening points, they were reacted with sulfuric acid, fumic sulfuric acid or elemental sulfur.

In the first step, granular char is produced by precipitation from the liquid phase in which asphalt is made to react with one of the above sulfurous substances.

In the next step, the char is activated continuously using the unique co-current, two-step fluidized furnace developed by us.

The product from our process shows good properties as regards specific surface area, methylene blue adsorption, pore distribution and mechanical strength. The vapor and liquid phase adsorption characteristics of our product are superior to those of market products.

We, Maruzen Oil Co., Ltd. are planning to commercialize this new process for production of high quality activated carbon.

\section{Acknowledgement}

The authors gratefully acknowledge the contribution and cooperation rendered by all members involved, particularly the members of MACH Project Team of Maruzen Oil Co., Ltd. and Activated Carbon Research Group of The Government Industrial Development Laboratory, Hokkaido.

The authors also wish to express their ap- 
preciation to Mr. Kazuo Miyamori, President of Maruzen Oil Co., Ltd., and Dr. Kanemasa Ijuin, Director of The Government Industrial Development Laboratory, Hokkaido for their permission to publish.

\section{References}

1) Kawabata, J., Tazaki, Y., Niikawa, K., Honma, S., Kudo, K., Hosoda, K., Ishibashi, K., Noda, Y. Mitsui, S., Reports of The Government Industrial Development Laboratory, Hokkaido, 8, 93 (1973).

2) U.S. $2,809,938$ (1957)

3) U.S. $2,900,351$ (1959).
4) Ger., 2,016,837 (1970).

5) Watari, S., Kato, T., Honda, H., J. Chem. Eng. Japan, 36, (4), 387 (1972).

6) Kudo, K., Hosoda, H., Honma, S., Ishibashi, K., Noda, Y., Mitsui, S., Nara, K., Sasaki, K., Tatsumoto, K., Komatsu, M., J. Fuel Soc. Japan, 52, (533), 325 (1973).

7) Dubinin, M. M., J. Colloid Interface Sci, 23, 487 (1967).

8) JIS K 1412 "Granular Activated Carbon".

9) Freundlich, H., Z. Physik. Chem., 57, 385 (1907).

10) Losev, G., ibid., 59, 284 (1907).

11) Boyd, G. E., Adamson, A. W., Myers, Jr., L. S., J. Am. Chem. Soc., 69, 2836 (1947). 